\title{
Sound Prohibited Zone for Smart Cities using loT
}

\author{
Bhawana A. Ahire* ${ }^{*}$ Sachin R. Sakhare
}

\begin{abstract}
One of the dominant causes of noise pollution is the disruptive honking while traveling on a road and is particularly problematic as well as resulting in irritating sound This results in many effects that need to be addressed taking into consideration stress, depression, mental and physical illnesses. The proposed system comprises of an embedded module that will be of great benefit to citizens of society adjacent to heavily populated roads, students studying in schools near crowded roads, patients admitted to roadside hospitals, etc. Noise Armor's alternative approach needs immense expenditure and personnel for both repair and surveillance as there is the need for expensive noise absorbers. By developing a real-time (smart) honking device that automatically allows vehicles on the road to reduce the volume of horn near conscious areas such as schools , hospitals, old-age homes, baby care centers and other organizations that are adversely damaged, our research aims to develop an effective solution for excessive honking.
\end{abstract}

Keywords: health hazards; IoT; smart honking; sound absorber; Sound Prohibited Zone; stress

\section{INTRODUCTION}

Now-a-days noise pollution is the major problem for society. Beeping the horn by cars has been a significant source of community noise pollution, resulting in health risks, frustration or impatience and injuries. As the number of vehicles are extremely increased day by day which results in traffic jams, dangerous and rough drivers and even accidents [1]. Mostly hospitals, schools old ages homes, baby care centers are situated near roadside. The patients, old people, babies and the students are having adverse effect on health due to honking of vehicles [15].

Over the decade, the urban population of India has been increased up to $31.8 \%$ during 2001-2011, as per the study [6]. Speedy urbanization has resulted into diverse public health difficulties, including environmental pollution $[15,16]$. It is required to initiate the actions to reduce the source of causing pollution in order to fulfil the ever growing population as well as development. Hence, it is essential to minimize factors causing pollution are more factual than their expulsion. Noise is one of the factor causing pollution under the air (Prevention and Control of Pollution) Act, 1981 [7].

Due to increase in vehicle the amount of pollution, that is generated by these vehicles have been increased significantly. In some areas such as in central cities, near hospital, school, baby care centers etc. honking (operating a horn to generate sound) is prohibited by law or regulation $[2$, 16]. Sound which is measured in decibels can be controlled according to the governance but there is no device to measure and control in real time. To develop an embedded module to reduce a noise intensity for reduce noise pollution. If the surrounding vehicle sound goes beyond the 65 decibels, then it results into annoying effects. Either some sound absorbers should be used to reduce the sound, but it is not economically feasible [17]. So, in order to deal with this problem, some technology should be developed to decrease the noise generated by honking of horn.

An embedded system has been developed to provide the solution for the above problem. This device deals with intervehicular contact with proportional (apposite) spectrum, frequency energy requirement) and quantity of material implemented using radio frequency (RF) signals. It is also possible to overlook the accidents caused by the noisy music played within the vehicles in the proposed module [5].

True-time, i.e. the intelligent honking scheme is intended to build a disincentive measure for repetitive honking. A large amount of noise pollution occurs at the time of traffic jam because of the beeping the horns which leads to irritation to the people living in the neighbourhood of the sensitive areas such as (schools, old age home, residential areas as well as hospitals, etc.) [6]. This problem can be easily solved by the currently available device as no horns in the community can be heard. Instead of in the atmosphere inside the receiver car, the source car sends RF signals that produce a beep sound.

In certain instances, the driver is unable to hear the horn, which may lead to an accident, due to the large amount of music [18]. The car's stereo system is shut down by accommodating the stereo system of the car with the horn, which results in reducing the number of incidents. In this system, the stereo system of the car is combined with the horn since the stereo system is automatically paused until the beep of the horn is detected, resulting in road accident avoidance [4]. Alongside the beep, a visual cue emerges that allows the concerned people accompanied by hearing loss to drive safely.

As per emergency, there is also facility of switching to traditional horn to deal with such circumstances such as sudden emergence of humans or animals using dual purpose switch. In the near future, there is a need to improve the existing system with additional design for the automation [14].

Our aim is to find a suitable solution to the problems described, which also leads to a user-friendly culture. In order to reduce noise pollution, IoT framework is used. By using the proposed system, health issues raised for senior citizens due to noise pollution is minimized.

In today's world, automating horn control of the vehicle is one of most essential demand. Our objective is to control the sound level of horn of vehicles based on location as well as reduce noise pollution using IoT framework. The proposed system consists of an embedded module to reduce noise 
intensity of horns automatically when the vehicle enters in the targeted areas.

The performance of this system results in an embedded module that benefits sensitive areas, i.e. residents of communities near busy roads, students studying in schools near busy roads, patients admitted to roadside hospitals.

In the following sections, the remaining paper is arranged: Section 2 focuses on similar work in terms of sound monitoring systems. The suggested approach used for the structure of an embedded module is discussed in Section 3, while Section 4 presents the results obtained, and Section 5 presents the conclusion.

\section{RELATED WORK}

Up to $55 \%$ of aggregate urban noise is caused by traffic produced by vehicles [1]. In [2], the authors researched the essence of horn blowing and examined it in all 107 vehicles. As a result of the research, two-vehicle and car / jeep drivers were found to be 30 percent and 26 percent respectively among all of these heavy vehicle drivers for highest honking, i.e. aggressive horns, as 37 percent of the total population of vehicles.

R. K. Mishra et al. evaluated and analysed traffic volume noise along has rapid transit system corridor [3]. Analysis of traffic volume noise is done with respect to the predicted and actual noise at selected corridors. In order to deal with the situation, the traffic noise pollution is controlled through the design of noise barrier along the road as well as suggested the people to use the public transport [3].

As per survey on the noise level at crowded places, the ambient air quality noise levels (AAQNL) at traffic signals is reported to be $5 \mathrm{dBA}$ whereas for commercial zones found in the spectrum of above/below $80 \mathrm{dBA}$, at some places $75 \mathrm{dBA}$ is also reported $[4,5]$. The effects of noise pollution on human health is very much hazardous which leads to severe headache, migraine, etc. The horns are classified based on their intensity levels by modelling the honk statistics i.e. Jam, Medius, Free. But in order to improve the classification results, pre-honk information is stored and utilised.

As per the Environmental Expert Council, studies show a continuous movement towards an increased cardiovascular hazard if the daytime emission boundary goes beyond 65 Decibels. The dangerous misclassifications have invalidated significant recent research on the extraoral effects of workplace noise. Studies on the health effects of noise are one of the most significant preconditions for a correct exposure assessment in the future [6].

As stated in Health programme of WHO(World Health Organization, 1994) [7], the conflicting outcome of noise is called as a change in the structure as well as physiology, that results in deterioration of practical capability. Temporary exposure to noise results in physiological changes that are easily unexpected. However, noise penetration of sufficient intensity causes duration changes that may not be reversible so readily.

Noise pollution is not regarded as a cause of mental illness, but the enhancement of suppressed mental disorders $[10,11]$ is intended to intensify and increase. It impairs job performance at school and at work, and reduces motivation [8]. Adults as well as children are also adversely affected. The study suggests that most attention should be paid to the effects of noise induced by excessive vehicle honking. Noise has been postulated to act as the factors that affects the environment [9].

The alternative noise absorber solution needs tremendous resources and manpower for repair and monitoring.

Honk monitoring system is also proposed by Atmadip D. et al. [19] which keeps track of excessive honking produced by the people near traffic signals. The proposed system calculates the number of horns at a certain period of time. If the number of horns goes beyond the limit, the system generates an alarm. The advantage of the system is that it is low-cost. The system if enhanced can be used for analysis of heavy traffic [19].

Acute noise exposure causes the autonomic and hormonal processes, resulting in transient variations such as high blood pressure and heart rate, too. To deal with the noise pollution scenario, Z. Zhao et al. [13] developed an adequate honk controlling system which administers blowing of the horn, locates the position of the sound generating vehicle, and envisions as an image captured by the road mounted cameras. But, the system cannot handle multi-SSL problem as well as localization error is the barrier for the challenging environment scenarios. The vehicle number plate recognition can also be added to improve the visualization results.

\section{PROPOSED METHODOLOGY}

The proposed system aims to create an efficient solution for excessive beeping the horn by implementing a smart honking system. The proposed system makes it easier for vehicles on the road to minimize horn volume near vulnerable areas such as schools, hospitals, old-age homes, baby care centres, and other adversely affected workplaces. An Admin has accessibility to add various targeted locations like hospitals, old-age homes, baby care centre and other workplaces. The GPS helps to discover the various location data. It enables to find specific places and to find the best path from real-time traffic. The targeted locations such as hospitals, signals, old age homes, baby care centres are extracted from the database server. User that is Drivers has to register and then login to see the Sound Prohibited Areas Zone List.

The proposed system consists of two modules, Software Module (Android App) and other is Hardware Module. The Software module consists of Database Server and an Android App which has GPS tracker and Admin section. The GPS helps to discover the various location data. The targeted locations (sensitive areas) such as hospitals, signals, old age homes, baby care centers are extracted from the database server. The performance of this system would result in an embedded module for the benefit of residents of communities close to sensitive areas such as highways, schools near busy roads, hospitals on the side of the road.

At the Traffic Signal where some drivers starts honking without waiting to turn the signal to green. Many of the 
drivers Shows No care or respect about people which required peaceful environment. As the smartphones are easily available with low cost, drivers are familiar with many of the applications. So this technology can be used which will benefited society. Figure 1 shows the structure of System Flow diagram. First the user's location information is extracted with the help of GPS. If the location is present in one of the Sound prohibited zone list then, auto ranging algorithm is applied for optimization to check the shortest distance. The horn of that vehicle is controlled with the help of hardware module installed in the vehicle.

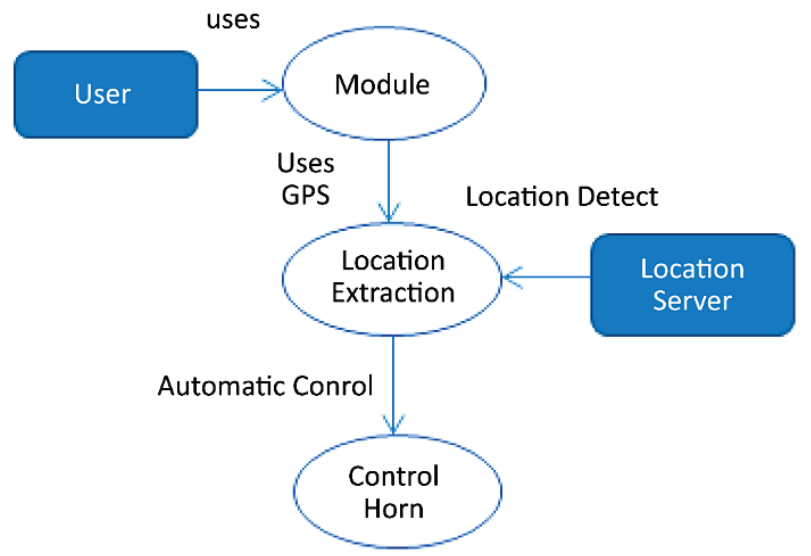

Figure 1 System Flow Diagram

Our proposed system aims at developing the real-time i.e. smart honing system because of which the intensity of the vehicles nearby sensitive areas i.e. schools, hospitals, baby care centers, ola-age homes, etc. is minimized. Sound which is measured in decibels can be controlled according to the governance but there is no device to measure and control in real time. To develop an embedded module to reduce a noise intensity for reduce noise pollution.

Fig. 2 focuses on the Architecture of the proposed system. The architectural diagram consists of e Hardware module consists of Arduino kit, WIFI module and Pizzo buzzer. In the proposed System, first the location is extracted, distance values are read from database then it will check frequency of horn if it is less than greater than minimum decibels then sends alert to driver and trigger the Buzzer and horn will be controlled.

The various targeted locations such as hospitals, signals, old age homes, baby care centres are extracted from the database server. The Auto Ranging Algorithm will be used to check if the vehicle is in the targeted locations or not. If it is, then android will send command to Arduino through WIFI module or Bluetooth. And the intensity of horn will be reduced. As a part of optimization, Auto Ranging algorithm is used which leads to accurate results.

When vehicle entered in the No honking or sound prohibited zone system first checks frequency of horn if Horn intensity greater Then it will sends alert to driver And Automatically Controlled the horn.

The Auto Ranging Algorithm will be applied to check if the vehicle is in the targeted locations or not. If vehicle is in targeted location, android app by using GPS will send command to Arduino through WIFI module. The Pizzobuzzer that is attached to horn will receive the command and intensity of horn that is decibel level of sound of horn will be reduced. When the vehicle passes through targeted locations, the intensity of horn is set to normal decibel as per the previous level.

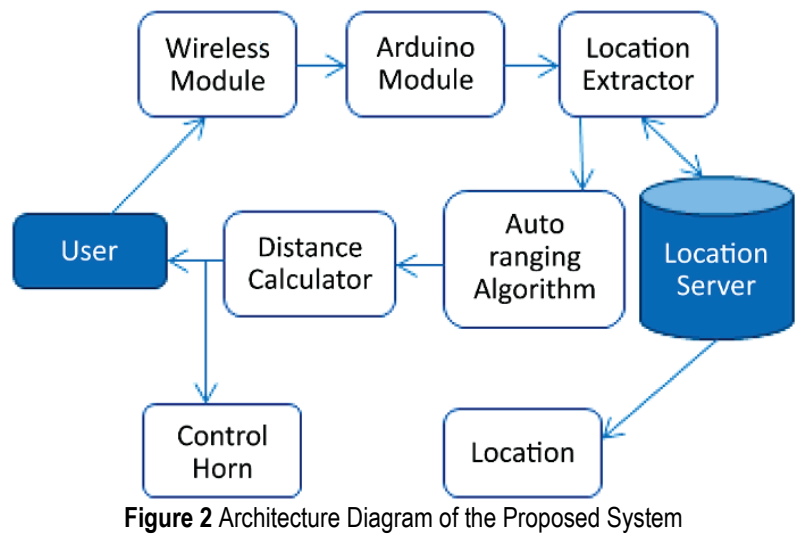

Big advantage to heart patients, kids and old people as the main target are the areas where these people are mostly suffered. The proposed system i.e. Sound Prohibited Zone for Smart Cities is to ensure that the Piezo buzzer that is attached to horn which will receive the command and intensity of horn that is decibel level of sound of horn will be reduced.

When the vehicle passes through targeted locations, the intensity of horn is set to normal decibel as previous. For the Smart Cities Project, Sound Prohibited Zone can surely become an important part. The system ensures to prevent noise pollution caused due to excessive honking of vehicles. An online monitoring system is to provide these data on the cloud in real-time stored in database.

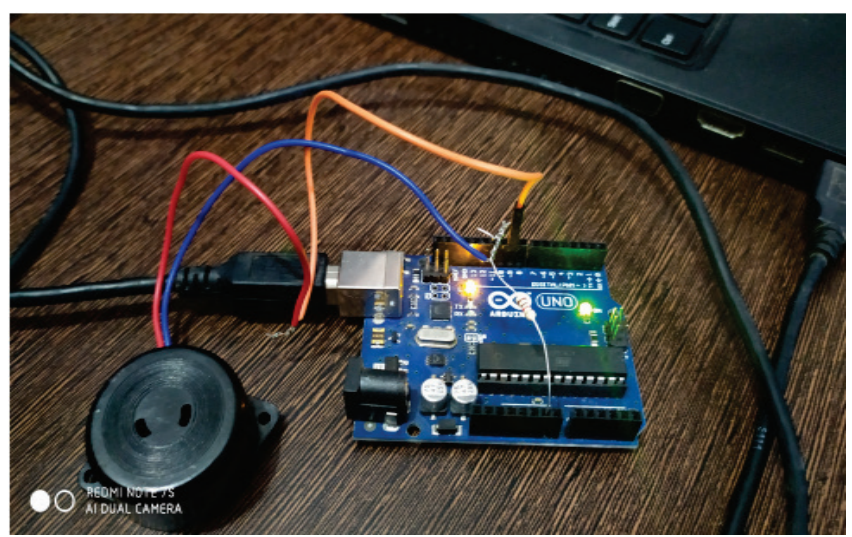

Figure 3 Circuit along with Pizzo buzzer

Sound Prohibited Zone System includes Android Application has Admin and User. In Admin login, It includes various operations like vehicle list which includes the driver list and is only accessible to the admin and not to the user, dustbin list (includes all the entries by the driver) and Add Zone List where admin can add new Sound Prohibited Zones. Admin has to enter location id to add new zone. When Location Id is entered the address of zone is automatically 
fetched by using the GPS so that location can easily added. As shown in the below Fig. 3, the circuit is shown with the Pizzo Buzzer.
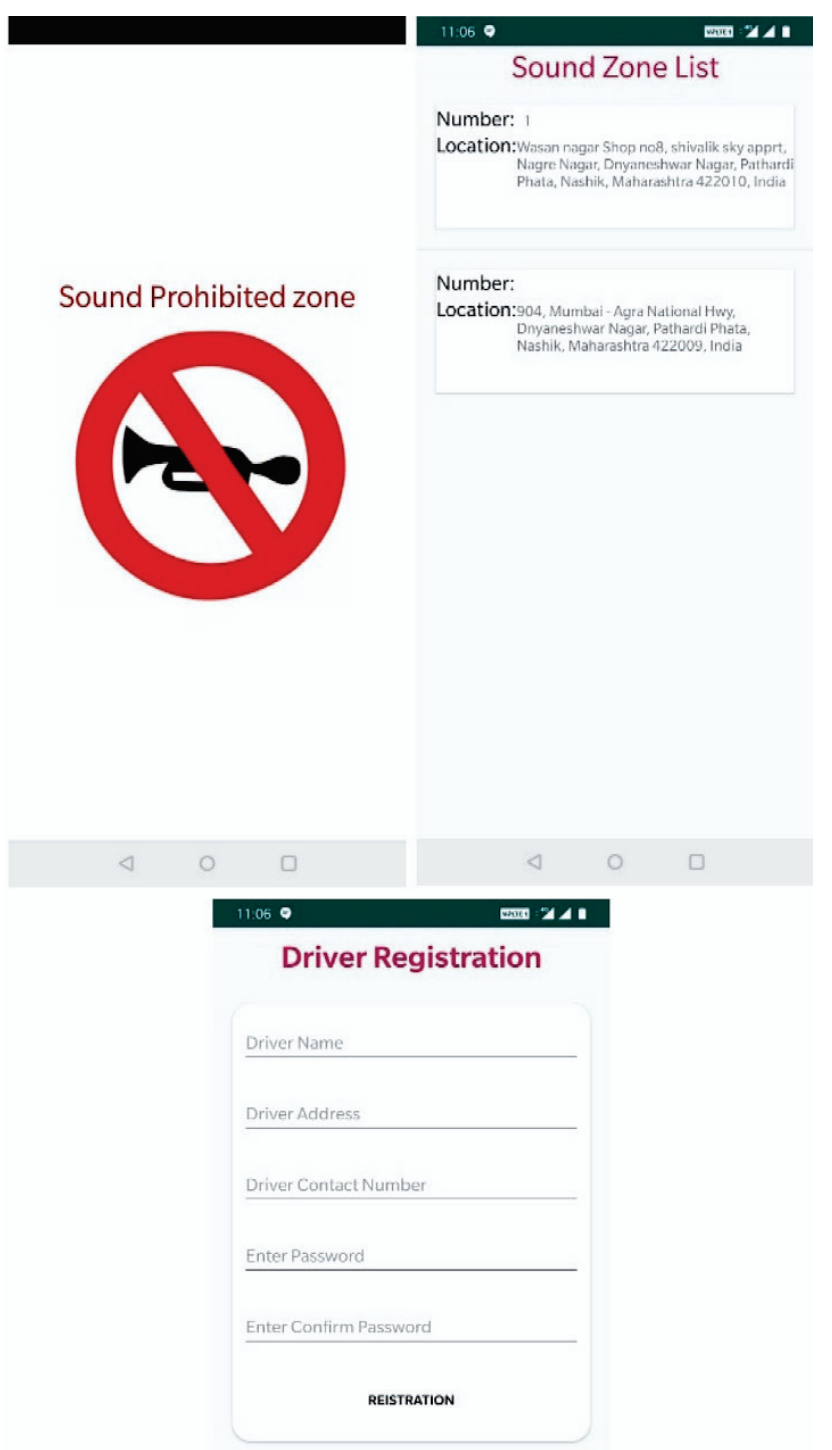

Figure 4 Snapshots (Driver Registration and Sound Prohibited Zone List)

As per snapshots shown in the above Fig. 4, driver registration has to be done. Sound Prohibited zone lists updating can be done by the admin. Admin can add the locations in the Sound Prohibited Zone list with image as well. On clicking that Image you will get to see the Location Id. All the entries by the driver or user are shown to Admin. User don't have access to Driver List. When clicked on the entry by driver, Admin can access its live location.

Admin can access the live location which is secure as only admin has access to the live location of the driver. User has to register to the application. Fig. 5 shows the snapshots after addition of Sound Prohibited Zone in the list by the admin. Registration includes Driver Name, Driver Address, Driver Contact No, and Password. It consist of all the zones entered by Admin. It will direct the driver to the Google Map and will inform if the vehicle is going to enter the zone. Current Location of Driver: The driver can see the its live location.

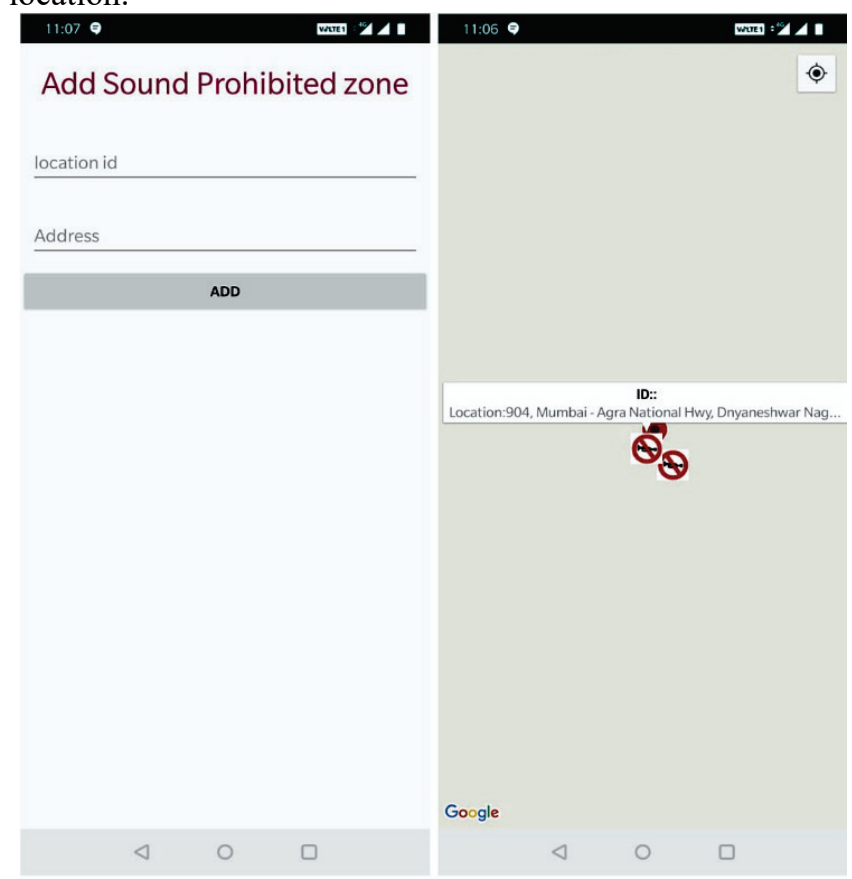

Figure 5 Snapshots (After addition of Sound Prohibited Zone)

\section{RESULTS}

The proposed system is compared with the existing system with respect to the different parameters like processing speed. The existing systems response time is less whereas, proposed system performs better in terms of processing time. Below graph (Fig. 6) shows the efficiency of the proposed system i.e. system performance.

\section{System performance}

25

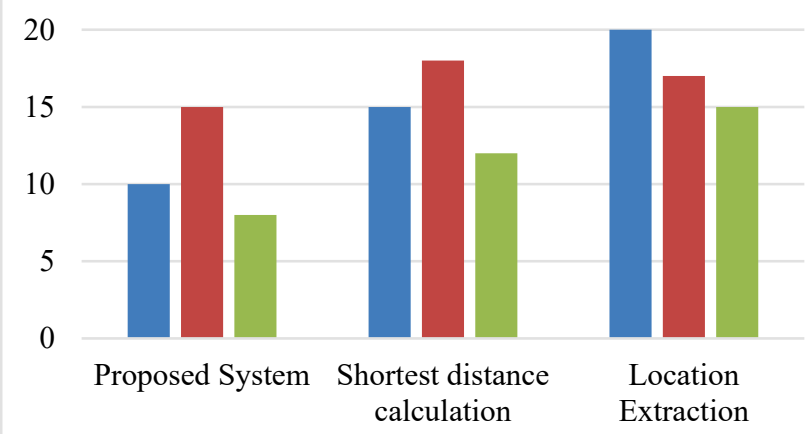

Figure 6 Graph showing System Performance i.e. Comparison with Existing Systems 
Accuracy of the proposed system near some of the crowded areas is observed to be around $80 \%$. The pictorial representation of the same is shown in the Fig. 7.

After applying the proposed system, the amount of noise pollution gets reduced. The reduction in the noise pollution is represented using graph in the Fig. 8.

\section{Accuracy in \%}

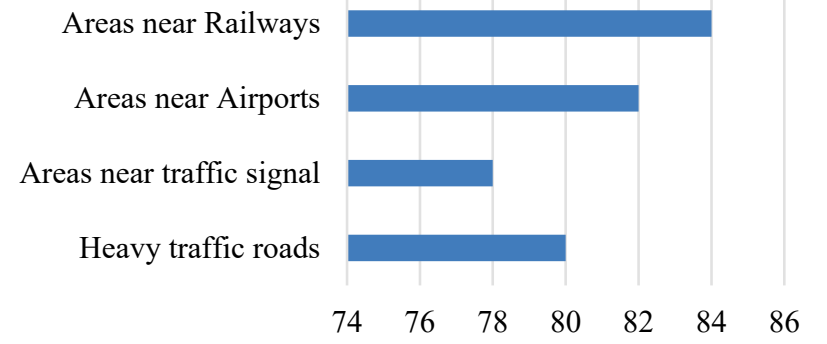

Figure 7 Graph showing System Accuracy near crowded areas.

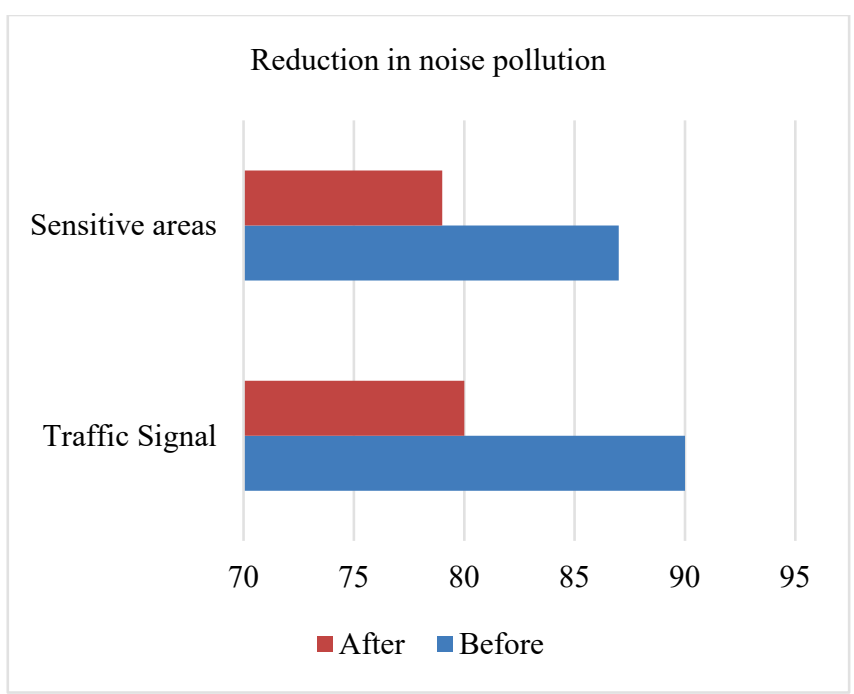

Figure 8 Graph showing Reduction in noise pollution

\section{CONCLUSION}

For the benefit of residents in communities near hightraffic highways, students studying in schools near busy roads, patients admitted to roadside hospitals, and people from different professions, the proposed framework results in an embedded module. To save many lives caused by their delay in reaching their desired destination browsers. Our proposed system aims at developing the real-time i.e. smart honing system because of which the intensity of the vehicles nearby sensitive areas i.e. schools, hospitals, baby care centers, ola-age homes, etc. is minimized.

The scope for the future work is inability to control the speed of the vehicle. The intensity of horn of vehicle is reduced but the speed of vehicle cannot be controlled. In addition to controlling the intensity of the horn, completely disabling of the horn once the person reaches the Sound Prohibited zone can be also worked on.

\section{Notice}

This paper was presented at IC2ST-2021 - International Conference on Convergence of Smart Technologies. This conference was organized in Pune, India by Aspire Research Foundation, January 9-10, 2021. The paper will not be published anywhere else.

\section{REFERENCES}

[1] Census of India 2011. Provisional Population Totals. Paper 2, Volume 1 of 2011. Rural-Urban Distribution India series 1. Office of the Registrar General \& Census Commissioner, India. 2011

[2] Chakrabarty, N. \& Reetesh, R. (2013). Aggressive Driving Case Studies and Mitigations in India. International Journal of Scientific and Research Publications, 3(2). www.ijsrp.org

[3] Dey, A., Arka, M., Raktim, P., \& Bansari, D. M. (2019). Design of a Smart Real-time Excessive Honking Control System. IOSR Journal of Electrical and Electronics Engineering (IOSR-JEEE), 14(6), 8-12.

[4] Goines, L. \& Hagler, L. (2007). Noise Pollution: A Modern Plague. Southern Medical Journal, 100(3), 287-294.

[5] Ising, H. \& Kruppa, B. (2004). Health effects caused by noise: evidence from the literature from the past 25 years. Noise Health, 6(22), 5-13.

[6] Joshi, V., Rajamani, N., Prathapaneni, N., \& Subramaniam, L. V. (2013). Traffic density state estimation based on acoustic fusion. 2013 IEEE International Conference on Acoustics, Speech and Signal Processing, Vancouver, BC, 478-482. https://doi.org/10.1109/ICASSP.2013.6637693

[7] Shalini, K. \& Kumar, B. (2018). Development of traffic noise model (TNM) using regression analysis in Varanasi city, India. International Journal of Civil Engineering and Technology, 9(4), 70-76.

[8] Ministry of Environment and Forests, Government of India. No. 14 of 1981, (29/03/1981) - The Air (Prevention and Control of Pollution) Act, 1981, amended 1987. Available from: http://www.moef.nic.in/legis/air/air1.html. (Accessed on 2011 Dec 6)

[9] Mishra, R. K., Parida, M., \& Rangnekar, S. (2010). Evaluation and analysis of traffic noise along bus rapid transit system corridor. Int. J. Environ. Sci. Tech., 7(4), 737-750.

[10] Niskar, A. S., Kieszak, S. M., Holmes, A. E., Esteban, E., Rubin, C., \& Brody, D. J. (2001). Estimated Prevalence of Noise-Induced Hearing Threshold Shifts Among Children 6 to 19 Years of Age: The Third National Health and Nutrition Examination Survey, 1988-1994, United States. Pediatrics, 108(1), 40-43. https://doi.org/10.1542/peds.108.1.40

[11] Noise. World Health Organization. 2011. Available from: http://www.euro.who.int/en/what-we-do/healthtopics/environmentand-health/noise. (Accessed on 2012 Aug $13)$.

[12] Vijay, R., Sharma, A., Chakrabarti, T. \& Gupta, R. (2015). Assessment of honking impact on traffic noise in urban traffic environment of Nagpur, India. Journal of Environmental Health Science and Engineering, 13(10). https://doi.org/10.1186/s40201-015-0164-4

[13] Sakhare, S. R. \& Ali, M. S. (2012). Genetic Algorithm Based Adaptive Scheduling Algorithm for Real Time Operating Systems. International Journal of Embedded Systems and Applications (IJESA), 2(3), 91-97.

[14] Sakhare, S. R. \& Ali, M. S. (2011). An Adaptive Framework for the Selection of Embedded Operating Systems. 
International Journal of Scientific \& Engineering Research, 2(8). Available from: https://www.ijser.org/researchpaper/AnAdaptive-Framework-for-the-Selection-of-Embedded-

Operating-Systems.pdf

[15] Sood, R., Sharma, S., \& Yadav, V. K. (2016). Real Time Smart Honking System. IEEE, International Conference on Information Technology (InCITe), 267-270. https://doi.org/ 10.1109/INCITE.2016.7857629

[16] Stansfeld, S. A. \& Matheson, M. P. (2003). Noise pollution: non-auditory effects on health. British Medical Bulletin, 68(1), 243-257. https://doi.org/10.1093/bmb/ldg033

[17] Tyagi, V., Kalyanaraman, S., \& Krishnapuram, R. (2012). Vehicular Traffic Density State Estimation Based on Cumulative Road Acoustics. IEEE Transactions on Intelligent Transportation Systems, 13, 1156-1166. https://doi.org/10.1109/TITS.2012.2190509

[18] Passchier-Vermeer, W. \& Passchier, W. F. (2000). Noise exposure and public health. Environmental Health Perspectives, 108(Supplement 1), 123-131. https://doi.org/10.1289/ehp.00108s1123

[19] Zhao, Z., Chen, W., Semprun, K. A., \& Chen, P. C. Y. (2019). Design and Evaluation of a Prototype System for Real-Time Monitoring of Vehicle Honking. IEEE Transactions on Vehicular Technology, 68(4), 3257-3267.

https://doi.org/10.1109/TVT.2019.2893777

\section{Authors' contacts:}

Mrs. Bhawana A. Ahire, Assistant Professor

(Corresponding author)

Department of Information Technology,

MVP Samaj's K B T College of Engineering,

Gangapur Road, Udoji Maratha Boarding Compound, Nashik, Maharashtra

422013, India

ahire.bhawana@kbtcoe.org

Dr. Sachin R. Sakhare, Professor

Vishwakarma Institute of Information Technology,

Survey No. 3/4, Kondhwa (Budruk), Pune - 411048, Maharashtra, India

sachin.sakhare@viit.ac.in

sakharesachin7@gmail.com 